\title{
Utilization of Vegetable and Fruit By-products as Functional Ingredient and Food
}

\author{
Ke Qi Lau, Mohd Redzwan Sabran* and Siti Raihanah Shafie \\ Department of Nutrition, Faculty of Medicine and Health Sciences, Universiti Putra Malaysia, Serdang, Malaysia
}

With the constant growth of the human population, the global demand for food is increasing annually. Food security is an arising issue due to decreased resources and massive waste production from the agricultural sector. For example, not all parts of fruits and vegetables are consumed by consumers, and this phenomenon can lead to huge amounts of food wastes that are produced globally. Moreover, non-utilized agriculture

OPEN ACCESS

Edited by:

Juliana Morales-Castro,

Durango Institute of

Technology, Mexico

Reviewed by:

Sapna Langyan,

National Bureau of Plant Genetic

Resources (ICAR), India

Diego A. Moreno,

CEBAS-CSIC, Food Science and Technology Department, Spanish National Research Council, Spain

J. Fernando Ayala-Zavala,

Centro de Investigación en Alimentación y Desarrollo, Consejo Nacional de Ciencia y Tecnología (CONACYT), Mexico

*Correspondence:

Mohd Redzwan Sabran mohdredzwan@upm.edu.my

\footnotetext{
Specialty section:

This article was submitted to Nutrition and Sustainable Diets,

a section of the journal

Frontiers in Nutrition

Received: 31 January 2021 Accepted: 29 April 2021

Published: 15 June 2021
}

Citation:

Lau KQ, Sabran MR and Shafie SR (2021) Utilization of Vegetable and Fruit By-products as Functional Ingredient and Food.

Front. Nutr. 8:661693.

doi: 10.3389/fnut.2021.661693 by-products, including seed coat, hull, husk, peels, seeds, and pomace, can cause environmental issues. Hence, efficiently utilizing food wastes, such as vegetable and fruit by-products, could be a way to increase food sustainability, and in line with the United Nations Sustainable Development Goal (SDG) to ensure sustainable consumption and production patterns. Moreover, certain agriculture by-products are reported to have a high nutritional value and could be potentially used as functional ingredient and food in the food industry. This review article summarizes findings on the development of new functional foods by utilizing different types of agriculture by-products, that is, vegetable and fruit by-products as ingredients. Furthermore, the nutritional values, processing methods, product acceptability, and potential uses of these vegetable and fruit by-products are also discussed. These by-products can be an alternative source of nutrients to support the global demand for functional foods and as one of the strategies to cope with food insecurity. Studies have shown that different types of fruit and vegetable by-products were well-incorporated in the development of functional foods, such as bakery products and dairy products. Of great importance, this review article provides an insight of the nutritional value, health benefits, and utilization of fruit and vegetable by-products.

Keywords: vegetable by-products, fruit by-products, food waste recovery, utilization of food waste, functional food, health benefit, food security

\section{INTRODUCTION}

In the agriculture field, postharvesting, processing, distribution, and consumption sectors could generate agriculture by-products that are wasted in huge amounts, which can contribute to the food waste problem (1). These food wastes are part of unintentional and intentional losses, which can lead to wastage of agriculture by-products (2). The unintentional losses include inadequate farming technologies and lack of proper transportation, whereas the intentional losses include due to human eating habits. Approximately $45 \%$ of fruits and vegetables are wasted worldwide, which is one of the categories with the highest wastage rate (1). The highest agricultural wastage is found in Europe, Latin America, North America, and Oceania, and it accounted for $\sim 10 \%$ higher than 
that of industrialized Asia (1). Moreover, the highest production wastage is found in Sub-Saharan Africa, which constitutes $\sim 20 \%$ (1).

It is of great concern that a massive amount of agricultural byproducts contributes to the food waste problem, subsequently, it can further lead to many environmental and economic issues (1). According to FAO, food loss and waste is the second highest cause of greenhouse gas emission. Statistically, 1.3 billion tons of wasted foods caused the emission of around 4.4 gigatons of greenhouse gas (1). Greenhouse gases are mostly originated from landfill emissions of decaying food, on-farm agriculture emission, electricity and heat in the manufacturing process, and the energy used for agriculture by-products that are lost or wasted. Clearly, these events can cause the greenhouse effect and lead to global warming and climate change, which might further affect the extinction of some animal species (3).

From the economic perspective, agricultural by-products and wastages can affect both the income of farmers and the expenses of consumers. For example, the cost of food waste is very high, especially in countries with a high population such as in China and the United States of America (4). It is evident as foods worth $\$ 32$ billion are thrown away yearly in China. Moreover, on average $\$ 1,600$ worth of food are wasted annually from a family of four in the United States of America. These large amounts of food wastes have a big impact on the income of farmers (1). In the sub-Saharan Africa, farmers earn only $<\$ 2$ in a day due to a large amount of postharvest losses. In fact, $\$ 940$ billion worth of foods are estimated to be lost or wasted annually, and the World Bank estimated \$40 million of economic gains could be achieved with just $1 \%$ reduction in postharvest losses, where this can benefit the small farmers (3). The extremely huge amount of wastage has drawn the attention of researchers to look for an alternative of utilizing fruit and vegetable by-products. Therefore, utilizing agricultural by-products not only helps the farmers and economics of customers, but also it can increase food sustainability and reduce food insecurity, especially for the underdeveloped countries. This review summarizes different types of food developed using fruit and vegetable by-products. Through this review article, the potential use of agricultural by-products is explored and discussed.

\section{AGRICULTURAL BY-PRODUCTS}

Agricultural by-products or wastes are the residues from the growing and processing of raw agricultural products, such as fruits, vegetables, meat, poultry, dairy products, and crops (5). Moreover, the wastes include animal wastes, such as manure and animal carcasses, food processing waste, crop waste, and dangerous and toxic agricultural waste, such as pesticides, insecticides, and herbicides. These agricultural wastes can exist in the form of liquid, slurry, or solid.

It is estimated that about 998 million tons of agricultural wastes are produced annually due to the expanding agricultural production. With the drastic demand, there is a significant increase in livestock waste, agricultural crop residues, and agroindustrial wastes. Hence, the expansion of the farming systems in developing countries increases the global agricultural wastes. It is evident as organic wastes generate up to $80 \%$ of the total solid wastes in any form, whereas the manure production can reach up to $5.27 \mathrm{~kg} /$ day $/ 1,000 \mathrm{~kg}$ live weight, on a wet weight basis (5). Agriculture by-products are also largely contributed by the improper utilization of fruits and vegetables that are commonly overproduced seasonally (6). Vegetable and fruit byproducts represent $44 \%$ of global food wastes by commodity, whereas roots and tubers contribute that of $20 \%$, and cereal constitutes that of $19 \%(1,7)$. In this review article, two types of agricultural by-products, that is, vegetable and fruit by-products are further discussed on their usefulness as functional ingredient and/or foods.

\section{Vegetable By-products}

Vegetable by-products are the secondary products that are often discarded or wasted during manufacturing or other stages of food processing. Up to one-third of vegetables could be wasted in the preparation process. Interestingly, certain parts of the vegetables are knowingly wasted due to their unfavorable taste or texture. For example, vegetable parts, such as hulls, bagasse, and seeds, are mostly discarded in the production line. For certain types of vegetables, such as broccoli, cauliflower, and pumpkin, the stem and leaves are not consumed and thrown away.

The seed coat, which is the outer layer that covers the seeds or beans, functions to protect them from external damages (8) and is one of the vegetable by-products. Seed coats are usually not consumed due to the texture and taste, except for some thin seed coats, such as peanut seed coats. In the canned food industry, seed coats are discarded in a large quantity as $\sim 22 \%$ of oilseeds and pulses worldwide are lost or wasted annually (1). The wastages of oilseeds and pulses are highest in the North Africa, West Asia, and Central Asia regions, and these by-products are mostly lost during the agriculture stage (1).

Unlike the seed coat, the hull is the hard-protecting cover of the seeds or grains that protects them during the growing period. Due to their hardness of texture, hulls are removed before cooking or manufacturing. Globally, hulls contribute to a large amount of food waste, especially rice hulls due to the high consumption of rice among the Asian countries (9). It is reported that $30 \%$ of the whole cereals are lost, and most of the wastages are due to human consumption and postharvest activities (1). To overcome this problem, hulls are used as a building material, fuel, and fertilizer (10) as one of the strategies to reduce wastage. Due to its high content of fiber and protein (11-13), the hull can be an alternative source of functional ingredient.

Not all vegetables have peels, unlike fruits. Tubers, gourd, and allium families contain peels, yet they are not normally consumed or used in food preparation. Therefore, vegetable peels are often discarded as kitchen or production wastes in the manufacturing line. Annually, large amounts of tuber and roots are wasted, and up to 5,814,000 tons of tubers and roots are wasted during the consumption stage in the North America and Oceania regions. In addition, Europe, North America, Oceania and industrialized Asia have the highest wastage of roots and tubers at the agriculture stage, where $\sim 45 \%$ of tubers and roots are lost globally (1). 


\section{Fruit By-products}

Fruit by-product is one of the principal roots of municipal solid waste, which has been the unresolved environmental menace (14). Municipal solid waste is defined as any substances discarded from residential, commercial, and industrial activity (15). Fruit peels or rinds are one of the by-products, which are commonly discarded during the consumption or manufacturing stage. It is the outer layer of fruits that functions to protect the fruits from environmental factors. Some fruits have thick and rough skin, such as pomegranate, whereas some fruits have a thin peel, such as mango. Most of the fruit skins are not consumed by consumers due to the rough texture and bitter aftertaste.

Other fruit by-products, such as seeds, are mostly consumed together with the fruits, such as watermelon and kiwi. In contrast, larger size seeds are not consumed, and they are mostly discarded after the flesh is consumed. Fruit seeds are rich in nutritional sources and have been used to develop functional foods (16). Fruit pomace is the remaining solid matter after juice extraction of fruits and might include seeds, skin, pulps, and stems for certain fruits. For example, apple pomace accounts $\sim 25 \%$ of apples, where wastes from the apple juice and cider industry can generate a massive amount of pomace (17). The wastage from apple pomace is especially higher in the Western countries, such as in Germany and New Zealand (18).

\section{NUTRITIONAL VALUE OF VEGETABLE AND FRUIT BY-PRODUCTS}

Findings in the literature showed that vegetable and fruit byproducts have high nutritional value $(19,20)$. Seed coats were reported to contain high dietary fiber. For instance, legumes seed coats are high in dietary fiber, ranging from 65 to $86 \%$ (19). Moreover, high content of dietary fiber has been reported in lemon, orange, bambangan, and grapefruit peels are also a rich source of dietary fiber $(21,22)$.

Apple pomace contains high dietary fiber compared to other fruit by-products, such as citrus peel (22). There are studies in the literature showed that apple pomace has been used as a functional ingredient and source of additional fiber in developing biscuits, cakes, and bread (23-26). Furthermore, pectin extracted from apple pomace has been used as an alternative source of gelatinizing agent that is used mainly to produce jam or jelly (27). Tomato pomace, which is high in dietary fiber and minerals, has been used as a functional ingredient to develop several functional foods, such as bread, muffin, and low-calories jam (28) Fuentes et al. (29) showed that the jam added with tomato pomace had $15-20 \%$ higher dietary fiber as compared to the commercial apricot jam. Other pomaces, such as grape, contain high protein and dietary fiber (30) and also a rich source of unsaturated fatty acids $(31,32)$.

Apricot kernel is also a potential functional food ingredient with high nutritional value. Studies in the literature have shown that apricot kernel has a high content of protein. Moreover, the apricot kernel has been used as a fat replacer in cookies and is incorporated into the development of noodles, bread, and cookies as reported in several studies $(33,34)$.
Moreover, the seed of fruits has been studied extensively. For example, fat extracted from rambutan seed showed high thermal stability, which suggested its possible uses in the food industry. The fatty acids of rambutan seed fats are mainly composed of oleic and arachidonic acid, which are omega- 9 and omega- 6 fatty acid, respectively (35). Furthermore, rambutan seed fats had a similar composition of fatty acids to cocoa fats and can be used to replace cocoa butter in chocolate production (36).

\section{HEALTH BENEFITS OF VEGETABLE AND FRUIT BY-PRODUCTS}

\section{Antioxidant Activity}

A study showed that seed coats from nuts and beans contain a high level of phenolic compound, which can contribute to strong antioxidant activity (20). The removal of seed coats of nuts has been associated with the reduction of antioxidant activity up to 90\% (20). Further study showed that flavonoids and saponins extracted from the black bean seed coats are well-retained, even after the baking process $(37,38)$, and these flavanoids and saponins from the black bean seed coat are suitable for food development due to the thermostability properties (39).

Moreover, several types of vegetable peels have shown to exhibit strong antioxidant properties. For example, potato peels were fortified into vegetable oil as antioxidant source in a study by Mohdaly et al. (40). The addition of potato peels improved the hydrolytic stability of vegetable oil and slowed thermal deterioration and stabilized the vegetable oil. In addition, the addition up to $200 \mathrm{ppm}$ of potato peels extract had comparable stabilization efficiency with the synthetic antioxidants. Furthermore, potato peels have been used as a functional ingredient in making cookies, wheat bread, and bakery goods in order to improve the nutritional properties and health benefits of the products (41-44).

Many types of fruit peels and pomace contain high phenolic compounds, which possessed strong radical scavenging activity. Some fruit peels, such as rambutan, mango, bambangan, and mangosteen peels, are reported to have high antioxidant activity and suitable to be used as natural antioxidants in the development of functional food $(21,45,46)$. Apple pomace is a good source of polyphenols and exhibits strong antioxidant activity (47-51). Polyphenols from apple pomace showed stronger radical scavenging activity than vitamin $\mathrm{C}$ and $\mathrm{E}$, which indicated that apple pomace could be a potential natural source of antioxidants (49). Apart from that, tomato pomace is a rich source of phenolic compounds and tocopherols $(31,32)$ for strong antioxidant activity $(50,51)$. Moreover, grape pomace has been used as a functional ingredient in many types of food development including breads, yogurt, cheese, muffins, salad dressing, cookies, and brownies (52-57). For example, the fortification of grape pomace has enhanced the health benefits of the products, especially in terms of antioxidant activity and increased the nutritional value of products.

\section{Antimicrobial and Antifungal Activity}

There are studies in the literature that found several types of vegetable peels with high antimicrobial and antifungal activities. 
In the study of Rakholiya et al. (58), phytochemicals of vegetable peels were analyzed, and the peels of Moringa oleifera showed the highest antimicrobial activity toward Gram-positive bacteria among all the fruits and vegetable peels studied. Furthermore, compatible results were shown in a study by Chanda et al. (59) in terms of the antimicrobial activity of fruits and vegetable peels. Moreover, lemon, papaya, and sapodilla peels showed high antimicrobial activity, especially toward Gram-negative bacteria, whereas papaya peels showed high inhibition toward fungi (58). Other peels, such as pomegranate peels, contain high antioxidant activity and antimicrobial activity against foodborne pathogens, such as Listeria monocytogenes, Escherichia coli, Yersinia enterocolitica, and Staphylococcus aureus $(46,60,61)$.

Besides its high antioxidant profile, mangosteen seed has antibacterial properties, where its antibacterial activity was highest among all the mangosteen parts (62). Indeed, the mangosteen seed also showed a better inhibition toward Grampositive bacteria (62).

\section{Anticancer Activity}

Citrus peels with high flavonoids levels possessed anticancer activity. A study lead by Lai et al. (63) showed that citrus peels have protective effects against cancer. Citrus peels significantly reduced the size of tumors of prostate cancer and showed strong anti-inflammatory, antiproliferative, and antiangiogenic activities, and enhanced apoptosis-inducing effects on prostate cancer. The high level of polymethoxyflavones in citrus peel could also effectively suppress azoxymethane-induced colonic tumorigenesis.

\section{Antidiabetic and Antihypocholesterolemic Activity}

Some fruits and vegetables by-products are found to have antidiabetic properties. The antidiabetic effects of mango byproducts were investigated in a study by Sarahí et al. (64). Mango by-products from the juice manufacturing industry including mango peels and pulps have shown insulin mimetic effect mainly due to the high level of soluble fiber, polyphenols, and carotenoids. Moreover, onion by-products with high dietary fiber showed hypoglycemic activities by effectively decreasing the starch digestibility and inhibiting the activity of alphaamylase (65).

In a study by Mildner-Szkudlar and Bajerska (66), bread fortified with grape by-product has shown a positive effect in reducing cholesterol levels in an animal model, where further study is warranted to evaluate its use among humans. In addition, extracts of flavonoid and saponins from black bean seed coats could inhibit cholesterol micellization up to $55.4 \pm 1.9 \%$, where the effect was superior compared to stigmasterol (39). Of great interest, the authors added black bean seed coats that can be incorporated to develop cholesterol-lowering functional food and to explore more possibilities of utilization of black bean and other seed coats (39).

Many types of fruit and vegetable by-products have shown to be rich bioactive compounds, which are closely related to the health benefits, such as antioxidant and antimicrobial activity.
More future studies could be done to incorporate the vegetable and fruit by-products for the development of new functional food to increase the nutritional security of food in the future market.

\section{FUNCTIONAL FOODS}

As people are getting more health conscience, the demand for functional food has increased over the past years. Functional food is defined as "food that has a positive impact on an individual's health, physical performance, or state of mind, in addition to its nutritious value" (67). The American Dietetic Association has defined functional food as "whole, fortified, enriched, or enhanced" food which is consumed as “... part of a varied diet on a regular basis, at effective levels" (68).

In the current market, the Asian Pacific and North American have the largest functional food market, which contributed to 34 and 25\%, respectively (69). The United States of America, Europe, and Japan are the top three countries, which contributed to $\sim 82 \%$ of the total sales for functional foods and supplements in the year 2003 (70). Functional food started with the fortification of certain vitamins or minerals into the food developments. In recent years, the development of functional foods has further proceeded to the fortification of one or more compounds, which could provide multiple health benefits (71).

\section{VEGETABLE AND FRUIT BY-PRODUCT AS FUNCTIONAL INGREDIENTS}

\section{Bread}

Bread is a common confectionery product, which is widely consumed worldwide. Based on a published report (72), \$358 billion worth of breads were consumed in the year 2016, a constantly increasing trend since 2007. Although breads are originated from Egypt, they are also consumed in Middle Eastern countries. Globally, the United States of America, China, and Russia are the top three countries with the highest bread consumption. These countries accounted for 32.7 million tons of bread consumption, equivalent to $\sim 25 \%$ of the total consumption of bread globally in the year 2016. Due to the high consumption of bread worldwide, many studies have incorporated vegetable and fruit by-products to develop functional bread, and these findings are summarized in Table 1.

It is found that the incorporation of vegetable and fruit byproducts increased the nutritional values of the bread. However, the physical and organoleptic acceptability are slightly affected with such incorporation in most of the studies. The color of bread and the texture profile are affected as the bread turns darker or harder, which subsequently affects the overall acceptability of consumers.

\section{Cookies and Biscuits}

Biscuits and cookies are popular confectionery products and are commonly consumed as a sweet dessert instead of savory food. Due to the low water activity and long shelf life, biscuits and cookies are also used as emergency food. However, biscuits and cookies are mostly low in nutritional values, such as fiber, 
TABLE 1 | Study and main findings of vegetable and fruits by-products utilization as functional ingredients in development of bread.

\begin{tabular}{lll}
\hline $\begin{array}{l}\text { Product } \\
\text { developed }\end{array}$ & $\begin{array}{l}\text { Vegetable and fruit } \\
\text { by-products }\end{array}$ & Study and main findings \\
\hline
\end{tabular}

Whole wheat bread Black bean seed In the study, $0.5 \%$ of black bean seed coat (BBSC) was incorporated for the development of coat (BBSC) whole wheat bread. The study found no significant difference in terms of baking properties and whole wheat bread. The study found no significant difference in terms of baking properties
texture parameters after the incorporation of BBSC. However, the crumb color showed significantly lower value in $L^{*}, a^{*}$, and $b^{*}$ score. Besides, all attributes during the sensory evaluation did not have significant difference with control except color, where the new product obtained higher score than control. The study also showed that more than $80 \%$ of flavonoids, saponins and anthocyanins were retained in baked bread, incorporated with BBSC.

Wheat bread $\quad$ Flaxseed hulls $(\mathrm{FH})$ In the study, 1-5\% flaxseed hulls (FH) were incorporated into wheat bread. The phenolics content was increased by $93 \%$ and the radicals scavenging ability as well as reducing power, increased by 176 and $220 \%$, respectively with the incorporation of $5 \%$ of $\mathrm{FH}$. Besides, the proteins digestibility decreased to $8 \%$. Based on the in vitro starch digestibility, expected glycemic index was not significantly affected with enrichment of $\mathrm{FH}$. It was found that $\mathrm{FH}$ enrichment decreased loaf volume and increased crumb hardness which affected texture of bread. In the sensory evaluation, no significant difference was observed on the overall acceptability of bread with the incorporation of $\mathrm{FH}$ up to $3 \%$.

Bread Pea hulls $(\mathrm{PH})$ Up to $10 \%$ of small-grained pea hulls (PHS) and coarse-grained hulls (PHC) were incorporated in bread. The study showed that pea hulls $(\mathrm{PH})$ contained high total dietary fiber (TDF), that is, 70.69\% in PHS and 93.29\% in PHC, respectively. The total baking lost and crumb porosity decreased with increasing amount of both PHS and PHC. The authors found that the functional properties of crust and crumb were affected with the addition of $\mathrm{PH}$. In addition, TDF of bread increased to 17.7 and $21 \%$ with the addition of $10 \%$ PHS and $10 \%$ PHC respectively. In the sensory evaluation, the acceptability of bread decreased with increasing amount of both PHS and PHC. The study found that up to $10 \% \mathrm{PH}$ could be incorporated in bread, with acceptable physical properties and sensory values, without altering the color.

Wheat bread Potato peels (PP)

The authors used $0,4,8$, and $12 \%$ of potato peels (PP) to be incorporated in wheat bread. An increase of PP in the formulation decreased the baking loss and bread volume. The incorporation of $12 \%$ PP significantly increased the dietary fiber (5.3-10.8 g/100 g DM) and cellulose $(0.5-2.5 \mathrm{~g} / 100 \mathrm{~g} \mathrm{DM})$. The study found that the texture profile of bread was affected with the incorporation of PP, where the hardiness, gumminess, modulus and adhesiveness were increased and the deformation energy, and springiness was reduced. Based on the sensory evaluation, $8 \%$ PP substitution had a better acceptability.

Wheat bread Pomegranate peel (PGP) Up to $10 \%$ of pomegranate peel (PGP) was incorporated in wheat bread. The antioxidant levels of bread increased from $1.8 \mathrm{mmol}$ TEAC per $\mathrm{g}$ (O\% PGP) to $6.8 \mathrm{mmol}$ TEAC per $\mathrm{g}$ (10\% PGP) and remained constant under 5 days storage. Besides, the concentration of free radicals decreased with increasing PGP substitution. In the sensory evaluation, no significant difference was observed as compared to the control in terms of acceptability for all attributes at all substitution level except taste and mouthfell of 10\% substitution as it caused a significantly lower score. The authors indicated that $2.5 \%$ of PGP substitution showed the highest acceptability with acceptable antioxidant value.

Bread Tomato pomace (TP) In this study, 6 and $10 \%$ of tomato pomace (TP) were incorporated in bread. Based on the preliminary analysis, TP contained $174.12 \mathrm{mg} / \mathrm{kg}$ lycopene, $32.66 \mathrm{mg} / \mathrm{kg} \beta$-carotene, 111.89 $\mathrm{mg} / \mathrm{kg}$ ascorbic acid and $865.77 \mathrm{mg}$ GAE/ $\mathrm{kg}$ total phenolics. Besides, TP was found to be rich in minerals including potassium, magnesium, calcium and sodium. The moisture content, titratable acidity and bread crumb elasticity were significantly increased with the supplementation of TP, while specific volume and bread crumb porosity were found to be decreased. In term of sensory evaluation, the acceptability of bread was slightly decreased with the increasing supplementation of TP. It was found that bread with 6\% TP supplementation showed high sensory results and acceptable physiochemical properties.

Bread Grape pomace (GP) In the study, 2, 5, and 10 of grape pomace (GP) were incorporated in bread. The incorporation of GP significantly increased the antioxidant activity of bread samples, from $11.06 \%(0 \% \mathrm{GP})$ to $55.64 \%$ (10\% GP). Besides, the total phenolic content of bread increased by more than $150 \%$ with the $10 \%$ of GP fortification. The study also found that fortification of GP significantly affected the color of crust and crumb and texture of bread. The hardness was increased while the springiness and cohesiveness were decreased with the increasing amount of GP being fortified. In term of sensory evaluation, no significant difference was observed in shape symmetry, crumb color, pore structure and odor for all samples. It was found that 2 and $5 \%$ GP-fortified bread had high acceptability, compared to the $10 \%$ of GP-incorporated bread.

$L^{*}, L^{*}$ standard (indicates lightness); $a^{*}, a^{*}$ standard (indicates red/green coordinate); $b^{*}, b^{*}$ standard (indicates yellow/blue coordinate).

protein, and minerals (76). The incorporation of vegetable and fruit by-products increased the nutritional values of the product (Table 2).
As can be seen in Table 2, cookies and biscuits that were incorporated with vegetable and fruit by-products had improved nutritional properties, such as dietary fiber and minerals. 
TABLE 2 | Study and main findings of vegetable and fruit by-products utilization as functional ingredients in development of cookies and biscuits.

\begin{tabular}{ll}
\hline $\begin{array}{l}\text { Product } \\
\text { developed }\end{array}$ & $\begin{array}{l}\text { Vegetable and fruit } \\
\text { by-products }\end{array}$
\end{tabular}

Acha-based biscuits Soybean hulls $(\mathrm{SH})$

In the study, $0,2.5,5.0$, and $7.5 \%$ of soybean hulls flour (SH) was incorporated into acha-based biscuits. The incorporation of $\mathrm{SH}$ significantly affected the physical and functional properties of biscuits. It is found that an increment in SH level $(0-7.5 \%)$ increased the water absorption (1.50-1.92 g/g) and the emulsifying capacities (50.27-53.41\%), while decreased the bulk density $(0.68-0.65 \mathrm{~g} / \mathrm{ml})$ and the oil absorption capacity $(1.49-1.46 \mathrm{~g} / \mathrm{g})$. Besides, the incorporation of SH significantly increased the level of fiber (0.71 to $0.91 \%)$ and protein content (3.91 to 5.39\%) while decreased the carbohydrate content (69.07 to $59.66 \%$ ) of the acha-based biscuit. In sensory evaluation, there was no significant difference in term of color, crispiness, aroma and general acceptability after the incorporation of SH. Nevertheless, 7.5\% fortified biscuits had the highest acceptability in term of texture, which was significantly higher compared to the control. Nevertheless, the authors showed that $2.5 \%$ fortified biscuits were most preferred organoleptically.

Biscuits Potato peels fiber (PF)

Cookies Grape pomace (GP)

Cookies

Grape pomace (GP)

Cookies

Pomegranate peel (PGP)

Biscuits

Pomegranate peel (PGP)

Cookies

Apricot kernel (AK)
In the study, 0, 5, 10, and 15\% of potato peel fiber (PF) was incorporated in biscuits. Preliminary analysis showed that the dried potato peel contained $76.40 \%$ dietary fiber and $14.04 \%$ protein. The incorporation of PF increased the carbohydrate, ash and fat content while reduced the protein content of biscuits. Based on the sensory evaluation, acceptability of biscuits decreased with the increasing PF content. The authors found that $5 \%$ formulation was preferable as more than $5 \%$ incorporation resulted in dark crumb color, hard texture which subsequently affected the appearance and mouthfeel.

In the study, 20 to $30 \%$ of grape pomace (GP) was incorporated in cookies formula. The fortification significantly affected the color and texture of cookies. It was found that the dietary fiber, total phenolic content (TPC) and free-radical scavenging activity of cookies increased with the increasing fortification of GP. The dietary fiber of fortified products ranged from 3.17 to 5.82 $\mathrm{g} / 100 \mathrm{~g}$ and TPC of cookies increased from $23.98 \mathrm{mg}$ GAE/100 $\mathrm{g}$ (20\% GP) to $48.08 \mathrm{mg}$ GAE/100 $\mathrm{g}(30 \% \mathrm{GP})$. Based on the sensory evaluation, the fortification of GP did not significantly affect the overall acceptability of cookie samples.

\section{In this study, $5,10,15$, and $20 \%$ of GP were incorporated in cookies. It was found that} anthocyanin, total phenolic content (TPC), flavonoid, tannins and antioxidant activity of cookies significantly increased with increasing GP content. In addition, the color intensity was increased with the increasing GP amount and the maximum color intensity was found in cookies with $20 \%$ GP, where the fortification produced brown color in cookies. In term of sensory evaluation, $5 \%$ and $10 \%$ GP fortified cookies had significantly higher overall acceptability than control. Besides, 5\% GP fortified cookies had the highest organoleptic score in all attributes. The study showed that 20\% GP-fortified cookies with highest color intensity had the highest acceptability for color compared to others.

Up to $7.5 \%$ of pomegranate peel (PGP) was incorporated in cookies and the dietary fiber increased from 0.32 to $1.96 \mathrm{~g} / 100 \mathrm{~g}$ with addition of $7.5 \% \mathrm{PGP}$, which is more than 6 times higher than control. The supplementation of PGP significantly increased the minerals content, that is, calcium, sodium, potassium, iron, and zinc in cookies. It was found that the total phenolic compounds and antioxidant activity of cookies significantly increased with the increasing amount of PGP. Besides, the addition of PGP reduced the level of oxidative degradation where cookies with $7.5 \%$ PGP showed a lower free fatty acid $(0.20 \%)$ after 4 months of storage, compared to control samples $(0.22 \%)$ at the 2 nd month of storage. Although the overall acceptability of cookies of PGP was lower than control, it remained acceptable under supplementation of $7.5 \%$.

Up to $10 \%$ of pomegranate peel (PGP) was incorporated in the biscuits. It was found that PGP had considerable amount of dietary fiber, total polyphenol, $\beta$-carotene, calcium and iron. An increase of PGP incorporation significantly increased the hardness and decreased the cohesiveness and springiness of biscuits dough. The incorporation of PGP affected functional properties of biscuits where breaking strength was found to be increased, with a decreased spread ratio. Based on the sensory evaluation, biscuits with 7.5\% PGP addition were well-accepted.

In the study, up to $25 \%$ of apricot kernel (AK) were incorporated in the development of low-fat cookies as a fat replacer. The incorporation of AK significantly increased the total dietary fiber content of cookies and altered the color and texture of cookies. The hardness of cookies increased with increasing AK amount being incorporated, while the spread ratio was found to be decreased from $7.10(0 \%)$ to $5.89(25 \%)$. In the sensory evaluation, no significant difference was observed for overall sensory score at all concentrations of AK substitution.

(Table 2), the incorporations of vegetable and fruit by-products up to $10 \%$ produced high acceptability and high functional values

However, high-level incorporation could affect the texture and sensory results of cookies and biscuits. Based on the findings 
TABLE 3 | Study and main findings of vegetable and fruit by-products utilization as functional ingredients in development of noodles.

\begin{tabular}{|c|c|c|c|}
\hline $\begin{array}{l}\text { Product } \\
\text { developed }\end{array}$ & $\begin{array}{l}\text { Vegetable and fruit } \\
\text { by-products }\end{array}$ & Study and main findings & References \\
\hline $\begin{array}{l}\text { Low glycemic index } \\
\text { (Gl) noodles }\end{array}$ & Legume seed coat & $\begin{array}{l}\text { Legume seed coat (Bengal gram) and broken rice were incorporated for the development of } \\
\text { low glycemic index noodles. The incorporation of legume seed coat significantly increased the } \\
\text { moisture, crude fiber and ash content of noodles. Besides, the total dietary fiber of noodles } \\
\text { increased from } 5.86 \text { to } 9.10 \% \text { with the incorporation of legume seed coat, in which } 2.30 \% \text { are } \\
\text { soluble fiber and } 6.80 \% \text { are insoluble fiber. The incorporation of legume seed coat significantly } \\
\text { decreased the glycemic index of noodles, from } 66.43 \text { to } 56.13 \text {. }\end{array}$ & (81) \\
\hline Wheat noodles & $\begin{array}{l}\text { Pomegranate peel } \\
\text { (PGP) }\end{array}$ & $\begin{array}{l}\text { In this study, } 0,0.75 \text {, and } 1.50 \% \text { of pomegranate peel (PGP) were incorporated in wheat } \\
\text { noodles. The DPPH radical scavenging activity of wheat noodles increased from } 23.20 \% \text { ( } 0 \% \\
\text { PGP) to } 95.16 \% \text { ( } 1.50 \% \text { PGP). Besides, the pH of wheat noodles was significantly decreased } \\
\text { with the increasing amount of PGP. The color and texture of wheat noodles were altered with } \\
\text { the incorporation of PGP, where fortified noodles were darker and harder. Based on the } \\
\text { sensory evaluation, no significant difference was shown in terms of firmness and stickiness of } \\
\text { all samples. }\end{array}$ & (82) \\
\hline Noodles & Apricot kernels (AK) & $\begin{array}{l}\text { In the study, } 5,10,15,20 \% \text { of apricot kernel (AK) were incorporated in making noodles. An } \\
\text { increased amount of AK being incorporated increased the ash }(0.69-1.00 \%) \text {, lipid }(0.4-10.6 \%) \\
\text { and protein (11.5-14.5\%). Besides, the color of dried noodles incorporated with up to } 15 \% \text { AK } \\
\text { showed no significant difference with control. Nevertheless, the color of raw noodles and } \\
\text { cooked noodles were altered with such incorporation. The authors found that the optimum } \\
\text { cooking time of noodles decreased with increasing AK amount being incorporated and the } \\
\text { total acceptability of noodles decreased with increasing AK addition. }\end{array}$ & (83) \\
\hline
\end{tabular}

including emulsifying capacities and bulk density. Despite the slight changes in the color and texture, a low-level incorporation of vegetable and fruit by-products into the development of cookies and biscuits could be a good alternative for healthy snacks.

\section{Noodles}

Noodles have a history of more than 4,000 years, and it is one of the most popular staple foods, especially in the Asian countries. China, Indonesia, and India are the three countries with the highest consumption of noodles across the world. Wheat flour is the main ingredient in making noodles. On average, $20-50 \%$ of the usage of wheat flour is in the form of noodles (79). In fact, up to 103,620 million servings of instant noodles were consumed worldwide in 2018 (80). Noodles are served as savory dishes globally with the presence of soup or gravy, and instant noodles were also used as space foods (80). Due to the large market of noodles consumption worldwide, researchers have developed noodles with functional properties. Vegetables and fruits by-products have been incorporated into noodles to increase the nutritional value of noodles (Table 3).

The incorporation of vegetable and fruit by-products in noodles significantly increased the content of fiber and protein. It is shown that the addition of fruits and vegetables by-products decreased the glycemic index or increased antioxidant activity of noodles as the by-products contained high fiber and phenolic compounds. As the market is lacking a variety of low glycemic food, vegetable and fruit by-products with rich source of dietary fiber could be a useful functional ingredient in exploring more low-glycemic food development.

\section{Dairy Products}

Dairy products such as yogurt, cheese, and butter are produced using milk and are widely consumed across the world. In 2019, 513 million metric tons of milk were produced globally, where the European Union is the highest dairy producer (84). In addition, the European Union has contributed to more than $30 \%$ of the global milk production (84). Dairy production is expected to reach 880 million tons in the year 2021 (85). Due to the constantly increasing worldwide trend of dairy products and functional dairy products, more developments of functional dairy products are deemed important.

Vegetable and fruit by-products are well-incorporated into dairy products, such as salad dressing, cheese, and ice cream, and the findings are summarized in Table 4. They are also used as a fat replacer and natural colorant, which showed their wide potential as functional ingredients. As the natural colorant, the incorporation in ice cream showed high acceptability, but more studies could be done on new inventions, which involve a thermal process to indicate the stability of the colorant. In another study, the addition of grape pomace and tomato peels significantly enhanced the antioxidant activities of dairy products, without affecting the organoleptic acceptability of consumers $(57,86)$.

\section{Other Products}

As can be seen in Table 5, other types of food have been developed by adding vegetable and fruit by-products, and the addition improved the dietary fiber content. For example, the addition of mango seed kernel (88) and cauliflower byproducts (89) improved the nutritional values of traditional Indian cuisines. Other studies have used pomace $(26,28)$ to improve the product. For the development of jam (28), tomato 
TABLE 4 | Study and main findings of vegetable and fruit by-products utilization as functional ingredients in development of dairy products.

\begin{tabular}{ll}
\hline $\begin{array}{l}\text { Product } \\
\text { developed }\end{array}$ & $\begin{array}{l}\text { Vegetable and fruit } \\
\text { by-products }\end{array}$
\end{tabular}

Semi-hard and hard Grape pomace (GP)

cheeses dressing

Ice cream

Tomato peels (TP)

Ice cream

Pomegranate peel (PGP)

Grape pomace (GP)
Two formulas were used where 0.8 and $1.6 \%$ of GP were incorporated in semi-hard and hard cheeses. No significant changes were observed for the physicochemical parameters of the cheeses after incorporation of GP except the $\mathrm{pH}$ value, where it was reduced. The total phenolic content (TPC) and radical scavenging activity (RSA) of cheeses increased with increasing GP content and ripening time. The study showed that semi-hard cheese fortified with 1.6\% Chardonnay GP before distillation had the highest TPC and RSA values. In term of microbial counts and proteolysis, no significant difference was observed after GP fortification.

In this study, 1-3\% GP, 0.5-1\% GP and 1-2\% GP were incorporated in yogurt, House Italian salad dressing and Thousand Island salad dressing respectively. During the 3 week storage at $4^{\circ} \mathrm{C}$, the fortified yogurt had reduced $\mathrm{pH}$ and increased viscosity. Lactic acid percentage and syneresis of fortified yogurt and salad dressing were stable in 3 week storage. In addition, up to $65 \%$ peroxide reduction was observed in the fortified products. Besides, the dietary fiber content of fortified samples ranged from $0.94-3.6 \%$, with total phenolic content and DPPH radical scavenging activity respectively ranging from 958-1,340 mg GAE/kg and 710-936 mg $\mathrm{AAE} / \mathrm{kg}$. Based on the sensory evaluation, no significant difference was observed in terms of overall liking of all fortified products, compared to the control products. In particular, the fortified Italian dressing showed no significant difference in all attributes including appearance, flavor, texture and consistency.

The carotenoids (lyco-red) extracted from tomato peels (TP) were used as natural colorants and antioxidants for the development of functional ice cream. The study showed that lycopene was the main component of lyco-red extract which contributed to $86.13 \%$, and followed by phytoene, phytofluene and b-carotene. Besides, the degradation of lyco-red increased with the increasing of temperature and decreasing of $\mathrm{pH}$. The authors found no significant difference of lyco-red degradation observed under $\mathrm{pH} 7$ to 10 and temperature ranging from 40 to $70^{\circ} \mathrm{C}$. Besides, more than 90 and $50 \%$ lyco-red was retained under condition of $100^{\circ} \mathrm{C}(30 \mathrm{~min})$ and $\mathrm{pH} 2$, respectively. $83.80 \%$ lyco-red pigments were retained at thermal condition of $100^{\circ} \mathrm{C}$ for duration of $180 \mathrm{~min}$. The Radical Scavenging Activity (RSA) and Ferric Reducing Antioxidant Power (FRAP) of ice cream increased with the increasing amount of lyco-red. Besides, ice cream supplemented with $5 \%$ lyco-red after 30 days storage showed more than $400 \%$ higher FRAP value as compared to control. Based on the sensory evaluation, ice cream was tested at storage period of 0 days and 30 days and ice cream with 1 to $4 \%$ had score ranged between 87 to 97 which were significantly higher as compared to control with score of 84 at 0 day storage period. Besides, ice cream with 2 and $3 \%$ of lyco-red incorporation showed the highest organoleptic acceptability.

In the study, 0.1 and $0.4 \%$ of pomegranate peel (PGP) were incorporated in for the development of ice cream. Besides, 2 to $4 \%$ of pomegranate seed oil was incorporated as milk fat replacement. It was found that PGP incorporation significantly increased the total acidity, decreased $\mathrm{pH}$ and altered the color of ice cream. The use pomegranate seed oil significantly increased the conjugated fatty acid content of ice cream and the incorporation of both PGP and pomegranate seed oil significantly increased the antioxidant and antidiabetic properties of ice creams. Based on the sensory evaluation, increase content of PGP significantly increased score of sour, astringent and color attribute. A significant increase of oxidized flavor was observed with the increasing level of pomegranate seed oil. It was found that ice creams formulation with $0.4 \%(\mathrm{w} / \mathrm{w})$ PGP and $2.0 \%(\mathrm{w} / \mathrm{w})$ pomegranate seed oil is suitable for the functional food development. pomace addition increased the content of dietary fiber up to 20 times.

\section{CONCLUSIONS: A WAY FORWARD IN UTILIZING VEGETABLE AND FRUIT BY-PRODUCTS}

Vegetable and fruit by-products are wastes from the agriculture, postharvest, processing, distribution, or consumption stages. Some of the by-products have been used as burning material, constructional material, or animal feed, whereas a large amount is being discarded. There are many types of agriculture by-products from the food industry and have been shown to have high nutritional qualities. By utilizing these by-products as functional food and ingredient, the cost of production can be lowered. Importantly, it can increase food sustainability and is one of the strategies to tackle the arising food security problem. Of great significance, findings from the literature showed that agriculture by-products, including vegetable and fruit by-products can be used to increase and enhance the nutritional value of functional foods. This review illustrates the potential of fruit and vegetable by-product as ingredients of value-added for food interventions. With proper hygiene protocol and processing technologies, utilizing these by-products in the functional food industry will be a good alternative to increase the choices of low-cost functional 
TABLE 5 | Study and main findings of vegetable and fruit by-products utilization as functional ingredients in development of other products.

\begin{tabular}{|c|c|c|c|}
\hline $\begin{array}{l}\text { Product } \\
\text { developed }\end{array}$ & $\begin{array}{l}\text { Vegetable and fruit } \\
\text { by-products }\end{array}$ & Study and main findings & References \\
\hline
\end{tabular}

Idli and mathi Mango seed kernel
$(\mathrm{MSK})$

Up to $40 \%$ of mango seed kernel (MSK) was incorporated in antioxidant rich idli and mathi. Idli incorporation of $10 \%$ MSK in both idli and mathi formulation were used for further analysis due to the highest acceptability for all attributes in sensory evaluation as compared to other formulation. It was found that $10 \%$ of MSK addition significantly increased the moisture content, crude fiber, crude fat, total ash and energy of both idli and mathi. The minerals including calcium, iron and magnesium content were significantly increased with $10 \% \mathrm{MSK}$ incorporation. Besides, the antioxidant activity of mathi increased from $31.8 \%$ to $37.0 \%$ and that of idli increased from $31.0 \%$ to $35.2 \%$ with incorporation of $10 \%$ MSK.

Dhokla, pancake Cauliflower and idli by-products

Jam Tomato pomace (TP)

Cake Apple pomace (AP)
The by-products of cauliflower are used to develop three new functional food recipes. In India, cauliflower is widely consumed or used in various types of cuisine, but the leaves are seldom utilized. The authors developed high fiber food recipes by using cauliflower leaves in making dhokla, pancake and idli. The dried cauliflower leaves had high fiber and iron content. Besides, the sensory evaluation of the food samples indicated the acceptability toward the incorporation of cauliflower leaves. In particulars, food samples with $2 \mathrm{~g}$ of cauliflower leaves flour are more organoleptically accepted.

Lyophilized tomato pomace (TP) was incorporated in 4 types of jam formulation. The TP jam without pectin has potential uses in food industry due to its higher stability under high temperature $\left(25-90^{\circ} \mathrm{C}\right)$. The TP jam formulations contained total carbohydrate content (17.23-43.81\%), proteins (1.32-2.03\%), fats (0.09-0.16\%) and energy value between $87.1-193.7 \mathrm{kcal} / 100 \mathrm{~g}$. As compared to commercial apricot jam, the dietary fiber of TP jam was 15 to 20 times higher. Based on the sensory evaluation, TP jam with pectin had higher score in terms of spreadability of jam. TP jams without pectin have comparably higher scores in tomato flavor, tomato odor, sour taste and sweet taste.

Up to $30 \%$ of apple pomace (AP) was incorporated in making cake. It was found that AP contained $10.16 \mathrm{mg} / \mathrm{g}$ total phenol content and $51.1 \%$ total dietary fiber, of which $36.50 \%$ was insoluble fiber and $14.60 \%$ was soluble fiber. An increased amount of AP incorporation significantly increased water absorption, mixing tolerance index and dough development time while decreased dough stability. Besides, $15 \%$ addition of AP in cake formulation significantly increased resistance to extension (336-742 BU) and decreased extensibility values (127-51 mm). The gelatinisation temperature of cake was shown to increase with increasing AP incorporation. In addition, the cold paste viscosity of cake was decreased from 1,760 to $970 \mathrm{BU}$ with addition of $15 \%$ AP. Although the incorporation of AP altered the physical quality of cakes, the volume and density of cakes was found to be decreased. Based on the sensory evaluation, no significant difference was found in terms of overall quality with up to $20 \%$ AP incorporation. The study found that the incorporation of $25 \%$ AP in cake increased the total dietary fiber from 0.47 (control) to $14.20 \%$ and total phenol content from 2.07 (control) to $3.15 \mathrm{mg} / \mathrm{g}$. food in the market for consumers. In addition, more research can be done on the underutilized agriculture by-products to seek more possibilities.

\section{AUTHOR CONTRIBUTIONS}

$\mathrm{KL}$ : writing-original draft. KL, MS, and SS: writing-review and editing. MS and SS: supervision. MS: project administration and resources. All authors reviewed and approved the final manuscript.

\section{FUNDING}

This research was funded by Putra Research Grant (Project No. GP-IPS/2018/9615800), Universiti Putra Malaysia, Selangor, Malaysia.

\section{REFERENCES}

1. FAO. Food Loss and Food Waste. Food and Agriculture Organization of the United Nations. (2015). Available online at: http://www.fao.org/food-lossand-foodwaste/en/ (accessed April 7, 2019).

2. Raak N, Symmank C, Zahn S, Aschemann-Witzel J, Rohm H. Processing- and product-related causes for food waste and implications for the food supply chain. Waste Manage. (2017) 61:461-72. doi: 10.1016/j.wasman.2016.12.027

3. FAO. Food Wastage Footprint: Iimpacts on natural resources. Food and Agriculture Organization of the United Nations. (2013). Available online at: http://www.fao.org/nr/sustainability (accessed March 11, 2019).

4. World Bank. Missing Food: The Case of Postharvest Grain Losses in SubSaharan Africa. Washington, DC: Natural Resources Institute \& Food and Agriculture Organization 60371-AFR (2011).

5. Obi F, Ugwuishiwu B, Nwakaire J. Agricultural waste concept, generation. Utilization and management. 
Niger J Technol. (2016) 35:957. doi: 10.4314/njt.v3 $5 \mathrm{i} 4.34$

6. Md Salim NS. Potential utilization of fruit and vegetable wastes for food through drying or extraction techniques. Novel Tech Nutr Food Sci. (2017) 1:15-27. doi: 10.31031/NTNF.2017.01.000506

7. Canxi C, Abhishek C, Alexander M. Nutritional and environmental losses embedded in global food waste. Resour Conserv Recycling. (2020) 160:104912. doi: 10.1016/j.resconrec.2020.104912

8. Beeckman T, De Rycke R, Viane R, Inze D. Histological study of seed coat development in Arabidopsis thaliana. J Plant Res. (2000) 113:139-48. doi: 10.1007/PL00013924

9. Toriyama K, Heong KL, Hardy B. Rice is life: scientific perspectives for the 21st century. In: Proceedings of the World Rice Research Conference held in Tokyo and Tsukuba, Japan, Los Baños (Philippines): International Rice Research Institute, and Tsukuba (Japan): Japan International Research Center for Agricultural Sciences. Metro Manila, (2005).

10. Kumar S, Sangwan P, Dhankhar R, Mor V, Bidra S. Utilization of rice husk and their ash: a review. Res J Chem Environ Sci. (2000) 5:126-9.

11. Ayo JA, Kajo N. Effect of soybean hulls supplementation on the quality of acha based biscuits. Agric Biol J N Am. (2016) 6:49-56. doi: 10.5251/ajfn.2016.6.2.49.56

12. Carré P, Citeau M, Robin G, Estorges M. Hull content and chemical composition of whole seeds, hulls and germs in cultivars of rapeseed (Brassica napus). Agronomie. (2016) 23:8. doi: 10.1051/ocl/2016013

13. Seczyk $€$, Swieca M, Dziki D, Anders A, Gawlik-Dziki U. Antioxidant, nutritional and functional characteristics of wheat bread enriched with ground flaxseed hulls. Food Chem. (2017) 214:32-8. doi: 10.1016/j.foodchem.2016.07.068

14. Rathnakumar K, Kumar Anal A, Lakshmi K. Optimization of ultrasonic assisted extraction of bioactive components from different parts of pineapple waste. Int J Agric Environ Biotechnol. (2017) 10:553-63. doi: 10.5958/2230-732X.2017.00068.7

15. Abas MA, Wee ST. Municipal solid waste management in Malaysia: an insight towards sustainability. SSRN Electron J. (2016). doi: 10.2139/ssrn.2714755

16. Mirhosseini H, Amid BT. Influence of chemical extraction conditions on the physicochemical and functional properties of polysaccharide gum from durian (Durio zibethinus) seed. Molecules. (2012) 17:6465-80. doi: 10.3390/molecules17066465

17. Pingret D, Fabiano-Tixier AS, Bourvellec CL, Renard CMGC, Chemat F. Lab and pilot-scale ultrasound-assisted water extraction of polyphenols from apple pomace. J Food Eng. (2012) 111:73-81. doi: 10.1016/j.jfoodeng.2012.01.026

18. Kennedy M, List D, Lu Y, Foo LY, Newman RH, Sims IM, et al. Apple pomace and products derived from apple pomace: uses, composition and analysis, in modern methods of plant analysis. In: Linskens HF, Jackson JE, editors. vol. 20. Analysis of Plant Waste Materials. Berlin: Springer Verlag (1999). p. 75-119.

19. Mamata M, Kamal GN, Chandru R, Vijayalakshmi KG. Processing and utilization of legume seed coat fibre for functional food formulations. Int $J$ Food Sci Technol Nutr. (2012) 6:78-98.

20. Arcan I, Yemenicioglu A. Antioxidant activity and phenolic content of fresh and dry nuts with or without the seed coat. J Food Composition Anal. (2009) 22:184-8. doi: 10.1016/j.jfca.2008.10.016

21. Hassan FA, Ismail A, Hamid AA, Azlan A, Al-sheraji SH. Characterisation of fibre-rich powder and antioxidant capacity of Mangifera pajang K. fruit peels. Food Chem. (2011) 126:283-8. doi: 10.1016/j.foodchem.2010. 11.019

22. Figuerola F, Hurtado ML, Estevez AM, Chiffelle I, Asenjo F. Fibre concentrates from apple pomace and citrus peel as potential fibre sources for food enrichment. Food Chem. (2005) 91:395-401. doi: 10.1016/j.foodchem.2004.04.036

23. Masoodi FA, Sharma B, Chauhan GS. Use of apple pomace as a source of dietary fiber in cakes. Plant Foods Hum Nutr. (2002) 57:121-8. doi: 10.1023/A:1015264032164

24. Rocha Parra AF, Ribotta PD, Ferrero C. Apple pomace in gluten-free formulations: effect on rheology and product quality. Food Sci Technol. (2014) 50:682-90. doi: 10.1111/ijfs.12662

25. Kohajdová Z, Karovičová J, Magala M, Kuchtová V. Effect of apple pomace powder addition on farinographic properties of wheat dough and biscuits quality. Chem Papers. (2014) 68:1059-65. doi: 10.2478/s11696-0140567-1

26. Sudha ML, Baskaran V, Leelavathi K. Apple pomace as a source of dietary fiber and polyphenols and its effect on the rheological characteristics and cake making. Food Chem. (2007) 104:686-92. doi: 10.1016/j.foodchem.2006.12.016

27. Canteri-Schemin MH, Fertonani HCR, Waszczynskyj N, Wosiacki G. Extraction of pectin from apple pomace. Brazilian Arch Biol Technol. (2005) 48:259-66. doi: 10.1590/S1516-89132005000200013

28. Belović MM, Torbica AM, Pajić-Lijaković IS, Mastilovic JS Development of low calorie jams with increased content of natural dietary fibre made from tomato pomace. Food Chem. (2017) 237:1226-33. doi: 10.1016/j.foodchem.2017. 06.045

29. Fuentes E, Carle R, Astudillo L, Guzmán L, Gutiérrez M, Carrasco G, et al. Antioxidant and antiplatelet activities in extracts from green and fully ripe tomato fruits (Solanum lycopersicum) and pomace from industrial tomato processing. Evid Based Complement Alternat Med. (2013) 2013:1-9. doi: $10.1155 / 2013 / 867578$

30. Beres C, Costa GN, Cabezudo I, Silva-James NK, Teles AS, Cruz AP, et al. Towards integral utilization of grape pomace from winemaking process: a review. Waste Manage. (2017) 68:581-94. doi: 10.1016/j.wasman.2017.07.017

31. Baydar NG, Ozkan G, Cetin ES. Characterization of grape seed and pomace oil extracts. Grasas Y Aceites. (2007) 58:29-33. doi: 10.3989/gya.2007.v58.i1.5

32. Llobera A, Cañellas J. Dietary fibre content and antioxidant activity of Manto Negro red grape (Vitis vinifera): pomace and stem. Food Chem. (2007) 101:659-66. doi: 10.1016/j.foodchem.2006.02.025

33. Dhen N, Rejeb IB, Boukhris H, Damergi C, Gargouri M. Physicochemical and sensory properties of wheat- Apricot kernels composite bread. LWT-Food Sci Technol. (2018) 95:262-7. doi: 10.1016/j.lwt.2018.04.068

34. Seker IT, Özboy-Özbaş O, Gökbulut I. Utilization of apricot kernel flour as fat replacer in cookies. J Food Process Preserv. (2008) 34:15-26. doi: 10.1111/j.1745-4549.2008.00258.x

35. Solís-Fuentes JA, Camey-Ortíz G, Hernández-Medel MdelR, Pérez-Mendoza F, Durán-de-Bazúa C. Composition, phase behavior and thermal stability of natural edible fat from rambutan (Nephelium lappaceum L.) seed. Bioresour Technol. (2010) 101:799-803. doi: 10.1016/j.biortech.2009.08.031

36. Issara U, Zzaman W, Yang TA. Rambutan seed fat as a potential source of cocoa butter substitute in confectionary product. Int Food Res J. (2014) 21:25-31.

37. Chavez-Santoscoy RA, Gutiérrez-Uribe JA, Serna-Saldívar SO, Pérez-Carrillo E. Production of maize tortillas and cookies from nixtamalized flour enriched with anthocyanins, flavonoids and saponins extracted from black bean (Phaseolus vulgaris) seed coats. Food Chem. (2016) 192:90-7. doi: 10.1016/j.foodchem.2015.06.113

38. Chávez-Santoscoy RA, Lazo-Vélez MA, Serna-Sáldivar SO, Gutiérrez-Uribe JA. Delivery of flavonoids and saponins from black bean (Phaseolus vulgaris) seed coats incorporated into whole wheat bread. Int J Mol Sci. (2016) 17:222. doi: $10.3390 /$ ijms 17020222

39. Chavez-Santoscoy RA, Gutiérrez-Uribe JA, Serna-Saldívar SO. Effect of flavonoids and saponins extracted from black bean (Phaseolus vulgaris L.) seed coats as cholesterol micelle disruptors. Plant Foods Hum Nutr. (2013) 68:416-23. doi: 10.1007/s11130-013-0384-7

40. Mohdaly AAA, Sarhan MA, Mahmoud A, Ramadan MF, Smetanska I. Antioxidant efficacy of potato peels and sugar beet pulp extracts in vegetable oils protection. Food Chem. (2010) 123:1019-26. doi: 10.1016/j.foodchem.2010.05.054

41. Curti E, Carini E, Diantom A, Vittadini E. The use of potato fibre to improve bread physico-chemical properties during storage. Food Chem. (2016) 195:6470. doi: 10.1016/j.foodchem.2015.03.092

42. Dhingra D, Michael M, Rajput H. Physico-chemical characteristics of dietary fibre from potato peel and its effect on organoleptic characteristics of biscuits. J Agric Eng. (2012) 49:25-32.

43. Han JS, Kim JA, Han GP, Kim DS, Nobuyuki K, Lee KR. Quality characteristics of functional cookies with added potato peel. Korean J Food Cook Sci. (2004) 20:607-13.

44. Kaack K, Pedersen L, Laerke HN, Meyer A. New potato fibre for improvement of texture and colour of wheat bread. Eur Food Res Technol. (2006) 224:199_ 207. doi: 10.1007/s00217-006-0301-5 
45. Ajila CM, Naidu KA, Bhat SG, PrasadaRao USJ. Bioactive compounds and antioxidant potential of mango peel extract. Food Chem. (2007) 105:982-8. doi: 10.1016/j.foodchem.2007.04.052

46. Okonogi S, Duangrat C, Anuchpreeda S, Tachakittirungrod S, Chowwanapoonpohn S. Comparison of antioxidant capacities and cytotoxicities of certain fruit peels. Food Chem. (2007) 103:839-46. doi: 10.1016/j.foodchem.2006.09.034

47. Cetković G, Canadanovic-Brunet J, Djilas SM, Savatović S, Mandic AI, Tumbas V. Assessment of polyphenolic content and in vitro antiradical characteristics of apple pomace. Food Chem. (2008) 109:340-7. doi: 10.1016/j.foodchem.2007.12.046

48. He Y, Lu Q, Liviu G. Effects of extraction processes on the antioxidant activity of apple polyphenols. CyTA-J Food. (2015) 13:603-6. doi: 10.1080/19476337.2015.1026403

49. Lu Y, Foo Y. Antioxidant and radical scavenging activities of polyphenols from apple pomace. Food Chem. (2000) 68:81-5. doi: 10.1016/S0308-8146(99)00167-3

50. Bravi M, Spinoglio F, Verdone N, Adami M, Aliboni A, D’Andrea A, et al. Improving the extraction of a-tocopherol-enriched oil from grape seeds by supercritical CO2. Optimisation of the extraction conditions. J Food Eng. (2007) 78:488-93. doi: 10.1016/j.jfoodeng.2005.10.017

51. Murthy KNC, Singh RP, Jayaprakasha GK. Antioxidant activities of grape (Vitis vinifera) pomace extracts. J Agric Food Chem. (2002) 50:5909-14. doi: $10.1021 /$ jf0257042

52. Walker R, Tseng A, Cavender G, Ross A, Zhao Y. Physicochemical, nutritional, and sensory qualities of wine grape pomace fortified baked goods. J Food Sci. (2014) 79:S1811-22. doi: 10.1111/1750-3841.12554

53. Hayta M, Özugur G, Etgü H, Seker IT. Effect of grape (Vitis ViniferaL.) pomace on the quality, total phenolic content and anti-radical activity of bread. J Food Process Preserv. (2012) 38:980-6. doi: 10.1111/jfpp.12054

54. Karnopp AR, Fugueroa AM, Los PR, Teles JC, Simoes DRS, Barana AC, et al. Effects of whole-wheat flour and bordeaux grape pomace (Vitis labrusca L.) on the sensory, physicochemical and functional properties of cookies. Food Sci Technol. (2015) 35:750-6. doi: 10.1590/1678-457X.0010

55. Maner S, Sharma AK, Banerjee K, Wheat flour replacement by wine grape pomace powder positively affects physical, functional and sensory properties of cookies. Proc Natl Acad Sci India B:Biol Sci. (2017) 87:109-13. doi: 10.1007/s40011-015-0570-5

56. Marchiani R, Bertolino M, Ghirardello D, McSweeney PL, Zeppa G. Physicochemical and nutritional qualities of grape pomace powderfortified semi-hard cheeses. J Food Sci Technol. (2016) 53:1585-96. doi: 10.1007/s13197-015-2105-8

57. Tseng A, Zhao Y. Wine grape pomace as antioxidant dietary fibre for enhancing nutritional value and improving storability of yogurt and salad dressing. Food Chem. (2013) 138:356-65. doi: 10.1016/j.foodchem.2012.09.148

58. Rakholiya K, Kaneria M, Chanda S. Inhibition of microbial pathogens using fruit and vegetable peel extracts. Int J Food Sci Nutr. (2014) 65:733-9. doi: 10.3109/09637486.2014.908167

59. Chanda S, Baravalia Y, Kaneria M, Rakholiya K. Fruit and vegetable peelsstrong natural source of antimicrobics. In: Mendez-Vilas A, editor. Current Research, Technology and Education Topics in Applied Microbiology and Microbial Biotechnology. Spain: Formatex Research Center (1998). p. 444-450.

60. Al-Zoreky NS. Antimicrobial activity of pomegranate (Punica granatum L.) fruit peels. Int J Food Microbiol. (2009) 134:244-8. doi: 10.1016/j.ijfoodmicro.2009.07.002

61. Shiban SS, Al-Otaibi MM, Al-Zoreky NS. Antioxidant activity of pomegranate (Punica granatum L.) fruit peels. Food Nutr Sci. (2012) 3:991-6. doi: 10.4236/fns.2012.37131

62. Lim YS, Lee SS, Tan BC. Antioxidant capacity and antibacterial activity of different parts of mangosteen (Garcinia mangostana Linn.) extracts. Fruits. (2013) 68:483-9. doi: 10.1051/fruits/2013088

63. Lai CS, Li S, Miyauchi Y, Suzawa M, Ho CT, Pan MH, Potent anti-cancer effects of citrus peel flavonoids in human prostate xenograft tumors. Food Funct. (2013) 4:944-9. doi: 10.1039/c3fo60037h

64. Sarahí RG, Itzel MGR, Iza FPR, Ofelia M, Minerva RG, Rosalía RC, Mechanisms related to the anti-diabetic properties of mango
(Mangifera indica L.) juice by-product. J Funct Foods. (2017) 37:190-9. doi: 10.1016/j.jff.2017.07.058

65. Vanesa B, Esperanza M, María AMC, Yolanda A, Rosa ME, Physicochemical properties and in vitro antidiabetic potential of fibre concentrates from onion by-products. J Funct Foods. (2017) 36:34-42. doi: 10.1016/j.jff.2017.06.045

66. Mildner-Szkudlar S, Bajerska J. Protective effect of grape by-product-fortified breads against cholesterol/cholic acid diet-induced hypercholesterolaemia in rats. J Food Agric. (2013) 93:3271-8. doi: 10.1002/jsfa.6171

67. Rincón-León F. Encyclopedia of food sciences and nutrition. 2nd ed. Functional Food. San Diego; London: Elsevier (2003). p. 2827-32.

68. American Dietetic Association. Position of the American Dietetic Association: functional foods. J Am Diet Assoc. (1999) 99:1278-85. doi: 10.1016/S0002-8223(99)00314-4

69. Vicentini A., Liberatore L, Mastrocola D. Functional foods: trends and development of the global market. Ital J Food Sci. (2016) 28:338-51. doi: 10.14674/1120-1770/ijfs.v211

70. Blandon J, Cranfield J, Henson S. Functional Food and Natural Health Product Issues: The Canadian and International Context. Guelph, ON: International Food Economy Research Group: Department of Food, Agricultural and Resource Economics (2007).

71. Siró I, Kápolna E, Kápolna B, Lugasi A. Functional food. Product development, marketing and consumer acceptance-a review. Appetite. (2008) 51:456-67. doi: 10.1016/j.appet.2008.05.060

72. IndexBox. Market Overview, in World-Bread And Bakery Product-Market Analysis, Forecast, Size, Trends and Insights. Walnut, CA: IndexBox (2020).

73. Kasprzak M, Rzedzicki Z, Effect of pea seed coat admixture on physical properties and chemical composition of bread. Int Agrophys. (2010) 24:149-56

74. Altunkaya A, Hedegaard RV, Brimer L, Gokmen V, Skibsted LH. Antioxidant capacity versus chemical safety of wheat bread enriched with pomegranate peel powder. Food Funct. (2013) 4:722-7. doi: 10.1039/c3fo30296b

75. Nour V, Ionica ME, Trandafir I. Bread enriched in lycopene and other bioactive compounds by addition of dry tomato waste. J Food Sci Technol. (2015) 52:8260-67. doi: 10.1007/s13197-015-1934-9

76. Ismail $\mathrm{T}$, Akhtar $\mathrm{S}$, Riaz $\mathrm{M}$, Ismail $\mathrm{A}$. Effect of pomegranate peel supplementation on nutritional, organoleptic and stability properties of cookies. Int J Food Sci Nutr. (2014) 65:661-6. doi: 10.3109/09637486.2014.908170

77. Srivastava P, Indrani D, Singh RP. Effect of dried pomegranate (Punica granatum) peel powder (DPPP) on textural, organoleptic and nutritional characteristics of biscuits. Int J Food Sci Nutr. (2014) 65:827-33. doi: $10.3109 / 09637486.2014 .937797$

78. Özboy-Özbaş O, Seker IT, Gökbulut I. Effects of resistant starch, apricot kernel flour, and fiber-rich fruit powders on low-fat cookie quality. Food Sci Biotechnol. (2010) 19:979-86. doi: 10.1007/s10068-0100137-4

79. Hou Gary G. Noodle processing technology. In: Asian Noodles: Science, Technology, and Processing. Hoboken, NJ: Wiley J \& Sons (2010). p. 99-140.

80. WINA, Global Demand. World Instant Noodles Association. (2019). Available online at: https://instantnoodles.org/en/noodles/market.html (accessed February 27, 2020).

81. Beniwal P, Jood S. Development of low glycemic index noodles by legume and cereal by-products incorporation. Int J Health Sci Res. (2015) 5:381-7.

82. Kazemi M, Karim R, Mirhosseini H, Hamid AA, Tamnak S. Processing of parboiled wheat noodles fortified with pulsed ultrasound pomegranate (Punica granatum L. var. Malas) peel extract. Food Bioprocess Technol. (2016) 10:379-93. doi: 10.1007/s11947-016-1825-8

83. Eyidemir E, Hayta M. The effect of apricot kernel flour incorporation on the physicochemical and sensory properties of noodle. Afr J Biotechnol. (2008) 8:85-90. doi: 10.5897/AJB08.906

84. Statista. Milk Consumption per Capita by Country. Statista Research Department. (2020). Available online at: https://www.statista.com/statistics/ 535806/consumption-of-fluid-milk-per-capita-worldwide-country/ (accessed February 27, 2020).

85. FAO. Milk and dairy Products in human Nutrition. Food and Agriculture Organization of the United Nations. (2013). Available online at: http://www. fao.org/3/i3396e/i3396e.pdf (accessed April 29, 2019). 
86. Rizk EM, El-Kady AT, El-Bialy AR, Charactrization of carotenoids (lyco-red) extracted from tomato peels and its uses as natural colorants and antioxidants of ice cream. Ann Agric Sci. (2014) 59:53-61. doi: 10.1016/j.aoas.2014. 06.008

87. Cam M, Erdogan F, Aslan D, Dinç M. Enrichment of functional properties of ice cream with pomegranate by-products. Food Chem. (2013) 78:C1543-50. doi: 10.1111/1750-3841.12258

88. Kaur A, Brar JK. Use of mango seed kernels for the development of antioxidant rich idli and mathi. Int $J$ Home Sci. (2017) 3:715-9. doi: 10.15740/HAS/FSRJ/8.2/ 368-374

89. Chauhan A, Intelli. Product development and sensory evaluation of value added food products made by incorporating dried cauliflower green leaves. J Nutr Food Sci. (2014) 5:340. doi: 10.1166/jnef.20 14.1051

Conflict of Interest: The authors declare that the research was conducted in the absence of any commercial or financial relationships that could be construed as a potential conflict of interest.

Copyright (c) 2021 Lau, Sabran and Shafie. This is an open-access article distributed under the terms of the Creative Commons Attribution License (CC BY). The use, distribution or reproduction in other forums is permitted, provided the original author(s) and the copyright owner(s) are credited and that the original publication in this journal is cited, in accordance with accepted academic practice. No use, distribution or reproduction is permitted which does not comply with these terms. 